\title{
Roll over Beethoven
}

Margaret Allan

James Cook University of North Queensland

\begin{abstract}
A 'work in progress' report on a project to develop applications of interactive media in the study of language.
\end{abstract}

My main interest in educational technology over many years has been in applications of technology in the teaching of English to speakers of other languages (TESOL).

The TESOL profession has a long tradition of using audio-visual technologies and materials. From a practical point of view, current developments in interactive technology mean that the variety of media with which teachers are already familiar can now be stored and accessed in more convenient ways. Photographs, audio and video recordings, graphics, text and CALL programs will be available, separately or in combination, via machines which are simple to operate. This range of media may not be new to the profession, but harnessing them together with microcomputers offers new and very different ways of interacting with stored audio-visual information. It faces us with new concepts to explore and there are many questions to be answered. What are the implications for second language learning of a resource which makes possible random access to and interaction with multimedia databases? What are the strengths and what the weak points of the technology? What roles are appropriate for the different media within the combination? How are these changed by the introduction of computers? In what ways and under what circumstances will teachers and learners want to use the technology? I have set up a project with the School of English of the University of Birmingham to explore some of these questions in relation to the study of spoken language. 


\section{The study of intonation}

Intonation is a topic which students of language and of linguistics traditionally find difficult, and probably for this reason it tends to be neglected. Compared to the wealth of study materials for other aspects of second language study, intonation is poorly served. Traditional explanations of attitudinal meanings associated with intonation patterns tend to use isolated sentences to exemplify them.

The description of intonation developed by Dr David Brazil at the University of Birmingham, most recently described in Brazil (1985), looks at the intonation system as it operates at discourse level and offers considerable insights into the function of intonation as a communicative tool. Brazil's description provides a particularly good way in to understanding, for example, how speakers use intonation to signal their perceptions of shared or differing viewpoints, or to indicate that it is someone else's turn to speak.

The project took as its first goal the development of appropriate technology to make this approach to the teaching of intonation more widely accessible to teachers and students of English.

\section{Interactive technology}

Clearly the use of audio recordings is indicated for the study of a feature which is central to speech. We then considered the potential of interactive audio, with a computer harnessed to compact disc recording. A common problem for those studying intonation is that they have difficulty hearing intonation features. This of course leaves them very unconfident about dealing with the topic. Interactive audio technology offers opportunities for a variety of practice in listening to recorded speech, which could help tackle that aspect of the problem. Apart from the benefits of putting precise, random access to examples of spoken language under the control of the user, what else does computer interactivity offer?

It can be a very mechanical process. Language teachers have certainly not been the only ones to feel disappointment with the traditional approach of computer assisted instruction, which was embodied in much of the early software and is now widely considered to be too prescriptive. (See, for example, Megarry, 1988).

There are useful lessons to be learned from the experience of developing and using Computer Assisted Language Learning (CALL). There is currently a search for alternatives to the didactic role typical of much traditional computer-based training. Some are exploring applications of artificial intelligence in language teaching programs and/or ways of involving the learner in decision-making activities at certain points of a 
narrative. (See for example Murray, 1985 and Coleman, 1987). Martin Phillips, in an insightful analysis of different models in CALL, comes to the conclusion that the most promising application to explore is that of the computer as a 'prosthetic device' (Phillips, 1987). He draws our attention to ways we can use computers to carry out tasks which are beyond the power of human brains, for example the detailed analysis of large corpora of texts. This use of the computer has strong appeal, because it seeks to capitalise on properties which are unique to the resource, thus assigning to it a role for which it is eminently well-suited.

\section{A model from another discipline}

A good example from another discipline is the Voyager Company's $C D$ Companion Series which uses a computer program to explore recordings of musical works. The Companion to Beethoven's Ninth Symphony demonstrates how a computer can be programmed to allow you to explore the inner workings of the music in very exciting ways. The user is offered a menu of choices, which include background information on Beethoven's world and guides to 'The Art of Listening', with examples of instruments, themes and transitions called up by the computer as required. This is a particularly good example of how interactive technology (in this case audio, combined with computer graphics and text) can perform different functions for different users.

\section{An interactive listening project}

Our approach is similar in that we start with a set of speech recordings on compact disc and then use the computer's power to search, sort and present examples of language use as the basis for study which is initiated by the user. We are using the computer as a kind of toolbox, containing a variety of programs.

We are seeking to bring together a way of analysing intonation which illuminates a problematic area and a technology which is particularly well suited to the development of listening skills. We are exploring the possibilities of combining a mixture of teaching, listening practice and user-initiated research with a pedagogic approach which takes as its starting point the evidence of language as it is used. In effect the aim is to encapsulate academic expertise in a way which makes it constantly available and readily accessible to a range of different users.

This last is an important point. These users might be teachers, seeking information they can use in their classes, or learners, working alone, or perhaps in class groups on appropriate research tasks set by their teacher. We are treating the recording as an information database, which is tagged with information about the intonation system. Our next task is to devise ways of making it possible for users to follow their own paths through this 
information and to create their own programs from it. Jaquetta Megarry, discussing the possibilities opened up by programs like HyperCard, comments: "Too often we hand the learner an itinerary rather than a map of the terrain and a survival kit." (Megarry, 1988, p 174). This project is concerned with finding out more about the maps we might offer learners and how they actually use them.

'Interactive Intonation' is Stage One of the project, allowing for the testing of an approach to the use of interactive technology which can be applied to different language databases. We have considered two developments from there:

\section{Stage Two A: The Multimedia Language Database Project}

Here the approach is applied to video as well as audio databases, with an extension of the analysis to non-verbal features of interactions. In addition, interactive tools for the study of vocabulary and grammar will be introduced.

\section{Stage Two B: The Talking Dictionary Project}

A 'talking dictionary' for language learners will provide for exploration of the intonation and pronunciation features of spoken language as well as of the written word. The dictionary will also incorporate visuals as aids to the clarification of meaning.

\section{References}

Brazil, D. C. (1985). The Communicative Value of Intonation in English. ELR Monograph, University of Birmingham.

Coleman, J. A. (ed).(1987). The Interactive Videodisc in Language Teaching. Lochee Publications Ltd, Perthshire.

Megarry, J. (1988). Hypertext and compact discs: the challenge of multimedia learning. British Journal of Educational Technology, 19(3), 172183.

Murray, J. H. (1987). Humanists in an institute of technology: How foreign languages are reshaping workstation computing at MIT. Academic Computing, Sept. 1987.

Phillips, M. (1987). Potential paradigms and possible problems for CALL. System, 15(3), 275-287.

Author: Margaret Allan works in the School of Education at James Cook University of North Queensland, in Townsville.

Please cite as: Allan, M. (1991). Roll over Beethoven. Australian Journal of Educational Technology, 7(1), 19-22.

http:/ / www.ascilite.org.au/ajet/ajet7/allan.html 